\title{
BD8 certification of visually impaired people
}

\author{
Catey Bunce, Jennifer Evans, Scott Fraser, Richard Wormald
}

\begin{abstract}
Background-There is debate as to the completeness of the blind and partial sight registers in England and Wales. The purpose of this study was to estimate the proportion of eligible visually impaired people attending the hospital eye service who have a BD8 certificate and to identify factors associated with not being certified. Methods-Cross sectional survey of patients attending outpatients by medical record review analysed by multiple logistic regression.

Results- $51 \%(43 \%, 58 \%)$ of patients identified as eligible for registration did not have a BD8 certificate. The severity of visual impairment and the main diagnosis in terms of requirements for treatment, permanence of visual loss, and visual field loss were independently associated with non-certification. A partially sighted patient is estimated to be three times more likely to not have a BD8 certificate as a blind patient of similar diagnosis (adj OR: $3.4(95 \%$ CI: $1.7,6.8)$ ). A patient whose impairment is due to abnormal visual fields is estimated to be greater than three times more likely to be non-certified than one with low visual acuity of similar severity and cause (adj OR: 3.6 (95\% CI: 1.0, 12.7)). People whose impairment is potentially reversible are estimated to be eight times $(8.3(2.2,31.4))$ more likely not to have a certificate compared with people who had permanent non-treatable visual loss; and in those with permanent visual loss, a requirement for ongoing treatment was found to be associated with a lower odds of certification.
\end{abstract}

Conclusions-These data strongly suggest that epidemiological data collected during registration are biased towards permanent, non-treatable causes of visual loss and those which affect central rather than peripheral vision. Certain subgroups of the visually impaired are likely to be at greater risk of non-certification. BD8 guidelines need to be simplified.

(Br f Ophthalmol 1998;82:72-76)

Ophthalmic

Epidemiology,

Moorfields Eye

Hospital, City Road,

London EC1V 2PD

C Bunce

J Evans

S Fraser

$\mathrm{R}$ Wormald

Correspondence to: Miss C Bunce.

Accepted for publication 13 August 1997 and partial sight registers are therefore of concern, both to the individual who needs social service support for their disability, and to medical researchers requiring information on the causes of visual impairment.

In order to be registered, an individual must be examined by an ophthalmologist who certifies them blind or partially sighted by completing a form provided by the Department of Health, the BD8 certificate. On receipt of this certificate at social services departments, the patient is contacted and registered. In this paper we use the term "certification" to refer to the process by which an eligible person is given a BD8 certificate in order for them to be registered.

There is evidence from both population based surveys and hospital based studies that there is considerable unrecognised and unregistered visual impairment in the UK. ${ }^{1-4}$ The consequences for the unregistered visually disabled person have been well described. The effect on the analysis and interpretation of data collected during the course of registration is less clear.

There has been only one previous study on the prevalence of non-certification in eligible ophthalmic outpatients. ${ }^{4}$ This found that $7 / 27$ (26\%) blind and $42 / 68(62 \%)$ partially sighted, $49 / 95(52 \%)$ certifiable in total, outpatients attending three hospitals in the West Midlands area were not certified. This study had a relatively small sample size, particularly of blind people and it is not clear the extent to which the results may be extrapolated to the rest of the UK. There is a north-south trend in registration in England and Wales with a higher rate of registration per head of population the further north we go. ${ }^{5}$

\section{Methods}

We conducted cross sectional surveys of certification at the Western Eye Hospital (WEH) and Moorfields Eye Hospital (MEH). Both hospitals serve inner city populations but also provide tertiary referral functions. Retrospective review of medical records was used in order to avoid changing certification practice during the course of the study. Plots of the number of registrations by month revealed little between month variability in registration. A cross sectional period during the year preceding the study was therefore selected randomly. This period was defined in order to generate a sample of approximately 150 visually impaired people in each hospital. In WEH this period was of 1 month duration (April 1993) and in $\mathrm{MEH}$ of 1 week duration (August 1994).

The computerised patient administration systems were used to list all patients attending outpatient clinics during the time periods. The medical notes of these patients were reviewed in order to identify people eligible for BD8 certification. Table 1 shows definitions of certifiable 
Table 1 Study definitions of certifiable visual impairment

\begin{tabular}{llllll}
\hline \multirow{5}{*}{ Visual acuity } & \multicolumn{5}{l}{ Visual field code (see Table 2) } \\
\cline { 2 - 6 } & 1 or 2 & 3 & 4 & 5 & 6 \\
\hline$>6 / 24$ & Blind & P sight & & P sight & \\
$6 / 36$ or $6 / 24$ & Blind & P sight & P sight & P sight & P sight \\
$6 / 60$ & Blind & P sight & P sight & P sight & P sight \\
$3 / 60$ & Blind & Blind & P sight & P sight & P sight \\
$<3 / 60$ & Blind & Blind & Blind & Blind & Blind \\
\hline
\end{tabular}

P sight = partially sighted.

*If media opacities/aphakia.

Table 2 Study categorisation of visual fields by BD8 terminology

\begin{tabular}{|c|c|c|}
\hline Category & Definition & BD8 terminology \\
\hline 1 & Field contracted to $\leqslant 10^{\circ}$ & Very contracted, especially if the \\
\hline 2 & $\begin{array}{l}\text { Field contracted to: } \\
\leqslant 10^{\circ} \text { in the lower part of the field, } \\
>10^{\circ} \text { but } \leqslant 15^{\circ} \text { in the upper part of the field }\end{array}$ & $\begin{array}{l}\text { contraction is in the lower part of } \\
\text { the field }\end{array}$ \\
\hline 3 & Field contracted to $>10^{\circ}$ but $\leqslant 15^{\circ}$ & Very/marked contracted \\
\hline 4 & Field contracted to $>15^{\circ}$ but $\leqslant 20^{\circ}$ & Moderate contraction \\
\hline 5 & Gross field defect - for example, hemianopia & Gross field defect \\
\hline 6 & Field not in the above categories & Full field \\
\hline
\end{tabular}

Table 3 The "main cause" of visual impairment, classified according to the permanence of visual loss and need for active treatment

\begin{tabular}{lll}
\hline Category & Description & Diagnoses \\
\hline I & Permanent and requires no ongoing treatment & ARMD \\
& & Trauma/retinal detachment \\
& & Congenital/genetic/familial \\
& & Optic nerve pathology \\
& & Non-age related maculopathy \\
& & Retinitis pigmentosa \\
II & Permanent but requires ongoing treatment & Myopia \\
& & Glaucoma \\
& & Diabetic/vascular retinopathies \\
III & Potentially reversible & Uveitis \\
& & Cataract \\
& & Corneal/surface pathologies \\
\hline
\end{tabular}

Table 4 Characteristics of the study populations

\begin{tabular}{lll}
\hline Study factor & $\begin{array}{l}\text { Western Eye Hospital } \\
(n=129) \text { No } \%)\end{array}$ & $\begin{array}{l}\text { Moorfields Eye Hospital } \\
(n=194) \text { No }(\%)\end{array}$ \\
\hline $\begin{array}{l}\text { Severity of visual impairment: } \\
\quad \text { Blind }\end{array}$ & $41(32)$ & $61(31)$ \\
$\quad$ Partially sighted & $88(68)$ & $133(69)$ \\
Certifiable on field loss alone: & $93(72)$ & $175(90)$ \\
$\quad$ No & $36(28)$ & $19(10)$ \\
Yes & & \\
Sex: & $88(66)$ & $93(48)$ \\
Women & $44(34)$ & $101(52)$ \\
Men & & \\
Age (years): & $26(20)$ & $83(43)$ \\
$\quad \leqslant 64$ & $32(25)$ & $38(20)$ \\
$65-74$ & $43(33)$ & $17(9)$ \\
$75-84$ & $28(22)$ & $69(0,92)$ \\
$85-94$ & $77(3,93)$ & $35(18)$ \\
Median (range) & $17(13)$ & $46(24)$ \\
No of previous hospital visits: & $45(35)$ & $54(28)$ \\
$\quad \leqslant 3$ & $39(30)$ & $55(29)$ \\
$4-10$ & $27(21)$ & $14(1,261)$ \\
11-40 & $11(1,202)$ & $112(58)$ \\
$>40$ & & $63(32)$ \\
Median (range) & $50(39)$ & $19(10)$ \\
Main diagnosis: & $55(43)$ & \\
I* & $24(19)$ & \\
II & &
\end{tabular}

${ }^{\star} \mathrm{I}=$ permanent and no ongoing treatment; $\mathrm{II}=$ permanent but ongoing treatment; $\mathrm{III}=$ potentially reversible. pendently to check that the definitions of eligibility were applied consistently; good agreement was found (95\%).

Study subjects were also classified according to whether they were certifiable on the basis of visual fields alone:

(i) field loss certifiable: if certifiable due to an impaired visual field-for example, someone with a visual acuity of $6 / 24$ in their better eye but a visual field in category 1 ;

(ii) not field loss certifiable: if certifiable due to poor visual acuity.

For each patient identified as eligible for registration, information on the following was collected from their medical records: age, sex, date of first attendance at and number of visits to the hospital before the end of the cross sectional period; whether or not the patient was discharged during the cross sectional period; certification status and, if applicable, date of certification; main diagnosis - that is, cause of visual loss in the last eye to become impaired. The main diagnosis was classified according to the permanence of visual loss and need for active treatment (Table 3).

All analyses, unless otherwise stated, were conducted using STATA. ${ }^{6}$ The prevalence of non-certification by severity of visual impairment was estimated with $95 \%$ confidence intervals computed by the exact binomial method. Crude and adjusted odds ratios were estimated by logistic regression techniques, the first category of each study factor being used as baseline, either because its selection appeared to give the most meaningful results or because it contained the greater number of observations and hence its choice favoured precision. It should be noted that although the rare disease assumption is not valid here, the odds ratio is still a useful index of association. ${ }^{7}$ In the analysis of WEH data, adjustment was made for factors shown by univariate analysis to be significantly associated with the odds of non-certification. These factors were adjusted for in the second model fitted to MEH data to facilitate comparison and then any factors statistically significant in the second model were fitted in a third model. The third model was similar to the second model and so only the results of the simpler second model are presented here. Age and number of previous hospital visits were analysed as categorical to facilitate comparison with previous work. Because very few patients had been discharged, the impact of discharge on certification was not explored. Data from the two hospitals were not pooled because we wished to identify consistencies between hospital estimates.

\section{Results}

Overall, 323 people were identified as eligible for certification-129 at WEH and at 194 in MEH (Fig 1). Similar proportions of the people attending outpatient clinics at each hospital were eligible for registration $(8 \% v 7 \%)$.

Table 4 shows the characteristics of the study populations. The majority of the people identified as eligible for registration in each hospital were partially sighted rather than blind. At 


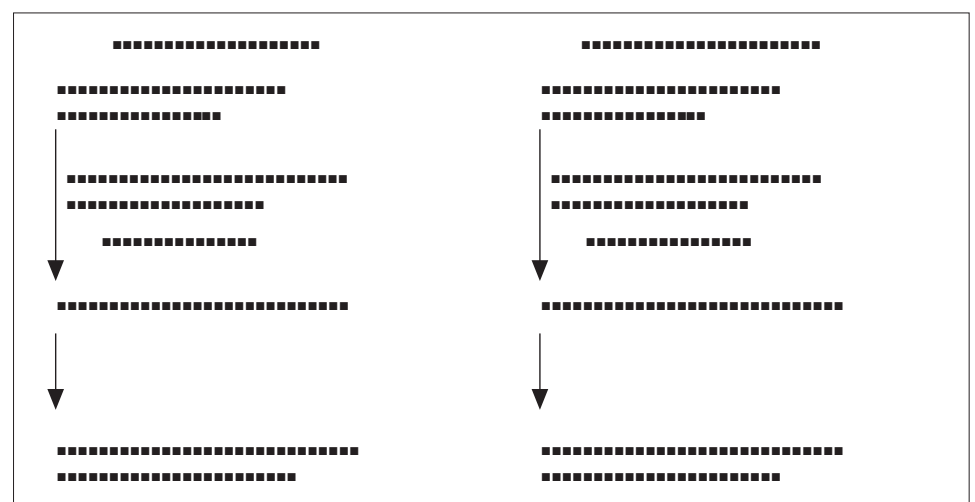

Figure 1 Flow diagram of the identification of study subjects.

Table 5 Estimates of the prevalence of non-certification in certifiable outpatients

\begin{tabular}{|c|c|c|c|c|c|c|}
\hline & \multicolumn{3}{|c|}{ Western Eye Hospital } & \multicolumn{3}{|c|}{ Moorfields Eye Hospital } \\
\hline & No & $\begin{array}{l}\text { Not } \\
\text { certified }\end{array}$ & $\begin{array}{l}\text { Prevalence } \\
\text { estimate }(95 \% C I)\end{array}$ & No & $\begin{array}{l}\text { Not } \\
\text { certified }\end{array}$ & $\begin{array}{l}\text { Prevalence } \\
\text { estimate }(95 \% C I)\end{array}$ \\
\hline $\begin{array}{l}\text { Crude estimate } \\
\text { Study factor: }\end{array}$ & 129 & 80 & $62 \%(53 \%, 70 \%)$ & 194 & 98 & $51 \%(43 \%, 58 \%)$ \\
\hline \multicolumn{7}{|c|}{ Severity of visual impairmer } \\
\hline Blind & 41 & 15 & $37 \%(22 \%, 53 \%)$ & 61 & 20 & $33 \%(21 \%, 46 \%)$ \\
\hline P sight & 88 & 65 & $74 \%(63 \%, 83 \%)$ & 133 & 78 & $59 \%(50 \%, 67 \%)$ \\
\hline
\end{tabular}

WEH, $28 \%$ of people were eligible for registration on the basis of fields alone compared with $10 \%$ at $\mathrm{MEH}$. More women $(66 \%)$ than men were identified at WEH, but similar numbers of each at $\mathrm{MEH}$. The majority of people identified were aged 65 years and above. Most people had made four or more visits to the hospital, with $20 \%$ or more in each hospital having made more than 40 visits. In both hospitals the majority of patients had a permanent cause of visual impairment; at WEH, 19\% had a potentially reversible cause compared with $10 \%$ at $\mathrm{MEH}$.

Table 5 shows considerable consistency between estimates of the prevalence of noncertification; $62 \%(53 \%-70 \%)$ of certifiable outpatients at WEH were not certified compared with $51 \%(43 \%-58 \%)$ at $\mathrm{MEH}$. Al- though there appears some evidence of greater non-certification at WEH this was not statistically significant. In both hospitals noncertification was statistically significantly more common in the partially sighted patients than the blind as shown by non-overlap of the $95 \%$ confidence intervals.

Table 6 shows the estimated effect of each study factor on non-certification. For simplicity this text relates to the slightly larger data set from $\mathrm{MEH}$, except where inconsistent with WEH. These data provide strong evidence of independent associations between certification and the severity of visual impairment, its main cause, and its effect on the visual field. A partially sighted ophthalmic outpatient is estimated to be three times more likely to be non-certified than a blind patient of similar diagnosis (adj OR: 3.4, (1.7, 6.8)). Noncertification is estimated to be greater than three times more likely in patients who are certifiable as a result of impaired visual fields than in those who are certifiable because of low visual acuity (adj OR: $3.6(1.0,12.7)$ ). This study provides strong evidence of an association between non-certification and the main diagnosis in terms of its requirement for active treatment and the permanence of visual impairment. Patients who require treatment for their permanent condition are estimated to be more than twice as likely to be non-certified as those who do not (adj OR: $2.7(1.4,5.3)$ ) while at greatest odds of non-certification are patients with potentially reversible main diagnoses (adj OR: $8.3(2.2,31.4)$ ). These data suggest that non-certification is more common in patients of 65 years of more than those under 65 and that there may be a trend of increasing odds with increasing age. It should be noted, however, that only the adjusted odds ratios comparing the older with the youngest age group of $\mathrm{MEH}$ achieve statistical significance. At $\mathrm{MEH}$ there was a decreasing trend in the odds of non-certification with an increase

Table 6 Estimates of the effect of each study factor on the odds of non-certification

\begin{tabular}{|c|c|c|c|c|}
\hline \multirow[b]{2}{*}{ Study factor } & \multicolumn{2}{|c|}{ Western Eye Hospital $(n=129)$} & \multicolumn{2}{|c|}{ Moorfields Eye Hospital II $(n=194)$} \\
\hline & Crude OR $(95 \%$ CI $)$ & $A d{ }^{\star} O R(95 \% C I)$ & Crude OR $(95 \%$ CI $)$ & $A d j^{\star} O R(95 \% C I)$ \\
\hline \multicolumn{5}{|c|}{ Severity of VI: } \\
\hline Blind & 1 & 1 & 1 & 1 \\
\hline $\mathrm{P}$ sight & $4.9(2.2,10.8)$ & $4.2(1.9,9.6)$ & $2.9(1.5,5.5)$ & $3.4(1.7,6.8)$ \\
\hline \multicolumn{5}{|c|}{ Cert on field alone: } \\
\hline No & 1 & 1 & 1 & 1 \\
\hline Yes & $1.3(0.6,3.0)$ & $1.7(0.7,4.3)$ & $4.2(1.3,13.0)$ & $3.6(1.0,12.7)$ \\
\hline \multicolumn{5}{|l|}{ Sex: } \\
\hline Women & 1 & 1 & 1 & 1 \\
\hline Men & $0.7(0.3,1.5)$ & $0.8(0.3,1.8)$ & $1.4(0.8,2.5)$ & $1.6(0.8,2.9)$ \\
\hline \multicolumn{5}{|l|}{ Age (years): } \\
\hline$\leqslant 64$ & 1 & 1 & 1 & 1 \\
\hline $65-74$ & $1.2(0.4,3.5)$ & $1.2(0.4,3.8)$ & $2.1(0.9,4.5)$ & $1.6(0.7,3.7)$ \\
\hline $75-84$ & $1.5(0.6,4.2)$ & $1.4(0.5,4.3)$ & $2.8(1.4,5.6)$ & $2.4(1.1,5.2)$ \\
\hline $85-94$ & $1(0.3,2.9)$ & $0.8(0.2,2.7)$ & $3.1(1.0,9.1)$ & $4.1(1.2,13.2)$ \\
\hline \multicolumn{5}{|c|}{ No of previous hospital visits: } \\
\hline$\leqslant 3$ & 1 & 1 & 1 & 1 \\
\hline $4-10$ & $0.8(0.2,2.5)$ & $0.9(0.2,3.4)$ & $0.5(0.2,1.2)$ & $0.4(0.1,1.2)$ \\
\hline $11-40$ & $0.9(0.3,3.3)$ & $1.2(0.3,4.8)$ & $0.4(0.1,0.9)$ & $0.2(0.1,0.7)$ \\
\hline & $0.3(0.1,1.1)$ & $0.4(0.1,1.6)$ & $0.2(0.1,0.4)$ & $0.1(0.0,0.3)$ \\
\hline \multicolumn{5}{|c|}{ Main diagnosist: } \\
\hline I & 1 & 1 & 1 & 1 \\
\hline II & $1.3(0.6,2.8)$ & $1.3(0.6,3.0)$ & $2.1(1.1,4.0)$ & $2.7(1.4,5.3)$ \\
\hline III & $10.2(2.2,47.9)$ & $8.2(1.7,39.9)$ & $7.9(2.2,28.3)$ & $8.3(2.2,31.4)$ \\
\hline
\end{tabular}

$\star_{\text {Adj ORs }}$ = adjusted for severity of visual impairment and main diagnosis.

$\dagger \mathrm{I}=$ permanent and no ongoing treatment; II = permanent but ongoing treatment; III = potentially reversible. 
in the number of times a patient has previously visited the hospital; this trend was not evident in WEH adjusted ORs.

\section{Discussion}

The blind and partial sight registers have a dual function: coordinating the provision of services to visually disabled people and providing data on the causes of visual loss in England and Wales. There has been debate over the completeness of the registers. In the mid 1980s Gibson et al showed in a small population based study that $90 \%$ of the blind and $50 \%$ of the partially sighted were registered. ${ }^{8}$ The RNIB Survey at the end of the 1980s, however, suggested that there was a threefold difference between the prevalence of visual disability in the population and the prevalence of registration for blindness and partial sight. ${ }^{12}$ At the beginning of the 1990s Robinson et al showed that over half of eligible patients attending three hospitals in the West Midlands were unregistered. ${ }^{4}$

Our overall findings show remarkable similarities to the West Midlands study even though our work was conducted in London and we used a different study design. In each of our hospitals, more than half of eligible people were not certified and in each we also obtained similar estimates of the prevalence of noncertification in blind and partially sighted people. It would be interesting to know whether this a general feature of BD8 certification within eye hospitals in the UK. For example, there are considerable regional differences in registration; does this correlate with activity within eye hospitals or is it related to other factors outside the hospital? For comparison purposes, other eye hospitals interested in auditing BD8 certification may wish to use the protocol for this study which is available through the audit desk of the Royal College of Ophthalmologists.

An important finding in the West Midlands study which is repeated here is that, irrespective of visual loss, people who are permanently visually impaired and are receiving ongoing treatment (for example, glaucoma) are less likely to be certified than those for conditions for which it is accepted there is no treatment (for example, macular degeneration). At WEH only $8 \%$ of patients with potentially reversible visual loss (for example, cataract) were certified and at MEH only $16 \%$. This is reflected in the analysis of causes of visual loss in the registered population. Only $5 \%$ of the population are registered blind or partially sighted due to cataract which is the commonest cause of visual impairment in the UK. ${ }^{39}$ Again, while this reflects the social role of the register implicitly (if not explicitly in the case of blindness registration), directed at people who are disabled permanently, it does make assessing the completeness of these data problematic as the "population at risk" of being registered varies with factors unrelated to changes in the incidence of visual loss.

A new finding from this study shows that people who have visual field loss alone are less likely to be certified than people whose central visual acuity is impaired. This effect is independent of the effect of diagnosis on certification. Although WHO definitions of blindness and visual impairment include visual fields, in general, visual fields are often ignored as a cause of visual impairment in many sources of data on blindness and low vision because of the difficulties of measurement and interpretation. It appears that this phenomenon also occurs in the registration statistics. Many glaucoma patients attend hospital over many years and may often be seen by non-consultants on review visits. This study highlights the importance of all non-consultant grades of ophthalmic staff taking responsibility for alerting patients and relevant consultants to the possibility of registration when visual fields are sufficiently restricted to warrant registration.

Our study had several weaknesses. Owing to resource considerations the studies in the two hospitals were conducted at different times; it would have been preferable to collect the data concurrently for comparative purposes. We were unable to collect enough cases in the younger age groups to provide reliable estimates of underregistration in children and working ages. Data were extracted retrospectively from medical records which meant that we were unable to collect information such as ethnic group which was not routinely recorded. We were dependent on the quality of information recorded and had no means to cross check that information. There are two possible sources of error this may introduce:

(1) Patients with low visual acuity may not have been corrected sufficiently to bring their vision up to non-registrable levels. Patients were classified according to their visual function during the selected cross sectional period. If there was insufficient information from any single visit we took the last recorded values on vision before the visit. In most cases, reference was made to best corrected or pinhole vision. However, it may be that a small proportion of our sample could have achieved better vision than that recorded in the notes.

(2) Patients eligible for registration on the basis of fields alone either may not have had their visual fields measured or that information may have been missing. This would mean that our results, which show that people with visual field loss were less likely to be registered, were conservative.

Assessment of, and indeed coverage of, the registers is hampered by difficulties over the definitions of people eligible to be placed on the registers. The guidelines are complex and ambiguous. We used a standardised version of the guidelines printed on the BD8 form and created our own (arbitrary) definitions for visual field categories such as "very contracted" etc. Review of the notes themselves was complex because of fluctuation in visual function over time. It is important not to forget the dual functions of the register: vague definitions may be useful to ophthalmologists and social workers concerned with the best provision of services to an individual but the same definitions make use of the register for 
epidemiological purposes problematic. Not only is it difficult to define the population that is eligible for registration but also people with visual acuity $<6 / 60$ or visual acuity $<6 / 24$ with opacities in the media, etc, or certain types of visual field loss, are not of interest in terms of national data on causes of visual loss. The WHO definitions could be much more usefully applied.

In addition, these definitions make it almost impossible to estimate population coverage accurately. If we consider a genuine assessment of the coverage of the registers at the population level, in order to estimate an expected coverage of say, $50 \%$ with a precision of plus or minus 5\% approximately 400 visually impaired people are required $(5 \% \alpha$ error). A population based study to identify this number of visually impaired people, depending on the age studied, but assuming a prevalence of visual impairment of $5 \%$, would require 8000 people to be examined. Large epidemiological surveys require simple examination techniques; the level of ophthalmic detail required to judge $\mathrm{BD} 8$ criteria is simply not cost effective or sensible.

In summary, there is increasing evidence that the criteria used for determining eligibility for entry onto the blindness and partial sight registers are too complex. This undoubtedly contributes to the high levels of noncertification. The registers could be much more useful for epidemiological analysis if the guidelines were simplified.

This study was supported by the Guide Dogs for the Blind Association. We acknowledge the help of Phillipa Cumberland in data extraction and to the medical records staff at the hospitals concerned for obtaining the notes for review. Thanks also to an anonymous referee for useful comments on the paper.

1 Bruce IW, McKennell AC, Walker EC. Blind and partially Bruce IW, McKennell AC, Walker EC. Blind and partially
sighted adults in Britain: the RNIB Survey. Vol 1. London: HMSO, 1991.

2 Walker EC, Tobin MJ, McKennell AC. Blind and partially sighed children in Britain: the RNIB Survey. Vol 2 London: HMSO, 1992

3 Wormald RPL, Wright LA, Courtney P, Beaumont B, Haines AP. Visual problems in the elderly population and implications for services. BMF 1992;304:1226-9.

4 Robinson R, Deutsch J, Jones HS, Youngson-Reilly S, Hamlin DM, Dhurjon L et al Unrecognised and unregisHamlin DM, Dhurjon L et al Unrecognised and unregis-

5 Evans JR, Wormald RPL. Epidemiological function of BD8 certification. Eye 1993;7:172-9.

6 Stata Corporation. Stata Statistical Software Release 5.0 College Station. TX, USA: StataCorp, 1997.

7 MacMahon B, Pugh TF. Epidemiology principles and methods. Boston: Little, Brown, 1970

8 Gibson JM, Lavery JR, Rosenthal AR. Blindness and partial sight in an elderly population. Br f Ophthalmol 1986;70: $700-5$.

9 Evans JR. Causes of blindness and partial sight in England and Wales 1990-1991 studies on medical and population subjects 57. London: HMSO, 1995 